\title{
Aldosterone, gut microbiome and hypertension: selected papers from APCH 2019
}

\author{
Michael Stowasser $\mathbb{1}^{1}$
}

Received: 15 December 2020 / Revised: 30 December 2020 / Accepted: 30 December 2020 / Published online: 27 January 2021

(c) The Author(s), under exclusive licence to Springer Nature Limited 2021

The 15th Asian-Pacific Congress of Hypertension was held in Brisbane, Australia between the 24th and the 27th November, 2019. As such, it represented one of the last face-to-face hypertension meetings before COVID-19 rendered these no longer feasible, at least for the foreseeable future. Few would disagree that face-to-face meetings facilitate a level of engagement among participants that videoconferencing struggles to achieve, and this meeting was no exception. A major strength of the Congress was the quality of the program, which opened with a day of satellite meetings, all of them investigator-driven. The topics for these satellites were handpicked by the Congress organizers to represent areas of hypertension research that were of particular current interest or in some way ground-breaking and therefore likely to attract leaders in their respective fields. When approached by the organizers, the Journal of Human Hypertension readily agreed to publish manuscripts prepared by satellite speakers, provided, of course, each was subjected to (and survived) peer review like any other submission. The result is this special edition of the Journal. Accepted submissions were received from speakers representing two of the four satellites: Aldosterone and Hypertension and Gut Microbiome and Hypertension. The first of these was particularly productive, representing seven of the nine papers appearing in this edition. Presumably this reflects the major renaissance in interest concerning the role of aldosterone excess in human hypertension that has occurred over the past few decades. This has arisen in part from the gradual realization that primary aldosteronism is much more common than previously thought, and that excessive mineralocorticoid receptor activation has deleterious effects on the cardiovascular and renal systems that go above and beyond blood pressure elevation. Papers were also received from the Gut Microbiome and Hypertension group, and provided a fascinating insight into the rapidly moving developments arising from this new and exciting field.

At the time of publication of this edition, not all the proposed submissions had been received or finally accepted for publication. So as to ensure the subject matter was still topical and relevant, we elected to publish only those that have completed the submission process up to this point but hope to have the remainder in print as soon as possible.

We do hope you enjoy this selection of what was an enormously informative and high quality group of presentations, discussed with vigour among attending participants in a way that we may not see again for some time.

\section{Compliance with ethical standards}

Conflict of interest The author declares no conflict of interest.

Publisher's note Springer Nature remains neutral with regard to jurisdictional claims in published maps and institutional affiliations.

Michael Stowasser

m.stowasser@uq.edu.au

1 Endocrine Hypertension Research Centre, University of Queensland Diamantina Institute, Princess Alexandra Hospital, Brisbane, QLD, Australia 